\title{
Farmers' Preferred Traits and Perceptions of Drought Stress on Rainfed Upland Rice Production across Two Rice Growing States of Nigeria
}

\author{
Christian Okechukwu Anyaoha \\ National Horticultural Research Institute, PMB, 5432, Idi-ishin, Ibadan, Oyo state, Nigeria \\ Email: kriskoty@yahoo.com \\ Uyokei Uba, Ejiro Onotugoma \\ National Cereals Research Institute Badggi. P.M.B 8 Bida, Niger state, Nigeria \\ Semon Mande \\ AfricaRice, Ibadan, Nigeria \\ Vernon Gracen \\ West Africa Centre for Crop Improvement (WACCI), University of Ghana, PMB 30, \\ Legon-Ghana \\ Nnabue Ikenna
}

National Root Crops Research Institute, Umudike, PMB 7006, Umuahia, Abia State, Nigeria

Received: May 26, 2019

doi:10.5296/jas.v7i3.15302
Accepted: August 17, 2019

Published: August 19, 2019

URL: https://doi.org/10.5296/jas.v7i3.15302

\begin{abstract}
The intermittent and widespread occurrence of drought in rainfed upland rice fields across sub-Sahara Africa has led to tremendous decrease in food security in the region. Although high yielding, drought tolerant varieties have been developed over years to mitigate this trend, limited adoption had been recorded for most of these materials. This study investigated farmers' perceptions on drought stress and their preferred traits in new upland rice varieties across two major upland rice growing states in Nigeria. Participatory Rural Appraisal was conducted among 119 rice farmers using comparative approach, probing and semi structured interviews. Result based on farmers knowledge of changes in rainfall pattern and preferred traits such as plant architecture and grain shapes in a new upland rice variety differed significantly across the two state. The results identified drought stress as one of the main constraints to upland rice production across communities. The ideal upland rice variety
\end{abstract}


desired by most respondents in both states should be of medium plant height $(115-130 \mathrm{~cm})$ characterized by white, long and bold grains. This study has demonstrated the importance of understanding farmer's desired traits in a new upland rice variety and the need to incorporate identified traits in creation of resilient new upland rice varieties adaptable to rain-fed upland rice growing regions of Nigeria.

Keywords: drought, participatory rural appraisal, rainfed, semi-structured interviews

\section{Introduction}

Rice is a popular food crop across different cultural, religious and geographical boundaries. It is consumed by the high and low income citizens in Sub-Sahara Africa (Ajah and Ajah, 2014). The demand for rice has been increasing (10\% per annum) in Nigeria more than in any other Africa country with an average Nigerian consuming about $24.8 \mathrm{~kg}$ of rice per year (FMARD 2012; Oladimeji and Abdulsalam, 2013; Ajala and Gana, 2015; Apata et al., 2018). This high demand for rice might be attributed to increasing population with changing consumer preferences due to rapid urbanization (Singh et al., 1997; Dauda and Dzivama, 2004; Aondoakaa, 2013). Rice is prepared and served in different forms based on localities and tribes in Nigeria. The preferred form among the Yorubas and Ibos includes Jollof and white rice served with sauce (Ologbon et al., 2012). It is also prepared into flour and cooked with boiling water to make Tuwo in Northern Nigeria.

Five major rice growing ecosystems have been reported in Nigeria: rainfed upland, rainfed lowland, irrigated lowland, deep inland water and mangrove swamp (Imolehin, 1991; Fashola et al., 2006; Van Oort and Zwart, 2018). Rainfed upland rice system is the dominant upland rice production system in Nigeria and is practiced across Abeokuta, Ado-Ekiti, Abakiliki, Ogoja in the south, Zamfara, Gombe and Yola in the north (Lontau, 2003; Nwaobiala and Adesope, 2013; Olanrewaju et al., 2018). Upland rice production is usually done by smallholder farmers with minimal crop production inputs throughout the growing seasons resulting to low grain yield not exceeding $2 \mathrm{t} \mathrm{ha}^{-1}$ (Atlin et al., 2004; Saka and Lawal, 2009; Ologbon et al., 2012). Rainfed upland rice production systems are characterized by low yield resulting from intermittent drought stress due to sole dependence on unpredictable rainfall as the main source of water (Kumar et al., 2014).

Unpredictable varying weather conditions with increasing human population across Sub-Sahara Africa have reduced availability of suitable land for agriculture (Hoffmann 2013; Arimi, 2014). Increasing variability in rainfall pattern across most rice growing communities in Nigeria has resulted to drought stress within rice growing seasons (Adejuwon, 2004; Agbola and Ojeleye, 2007; Ajetimobi et al., 2011; Ali et al., 2017). Increased drought stress adversely affects rice crop physiology which might lead to lower grain yield and quality (Bernier et al., 2008; Kumar et al., 2014). Unfortunately, most upland rice farmers in Nigeria practice rainfed agriculture and do not have access to the huge capital and technical expertise needed to establish and manage efficient irrigation systems in case of drought stress in their field. Development and release of resilient high yielding drought tolerant rice varieties with better response to agronomic inputs becomes very imperative if the negative effects of drought are to be mitigated (Saka and Lawal, 2009; Gumm, 2010). There is also need to 


\section{Macrothink Institute ${ }^{T M}$}

identify other characteristics apart from drought tolerance that are of significance to upland rice farmers which can be deployed as selection criteria in creation of new elite upland rice varieties (Kimani et al., 2011; Shebi et al., 2018). Partnering with farmers from the onset of varietal development ensures that their preferences for a new variety are captured and incorporated in a breeding programme to enhance ease of adoption (Witcombe and Joshi, 2003; World Bank, 2007; Atlin et al., 2006, Cobb et al., 2019). Interaction with farmers in targeted locations will not only ensure that farmer's preferences are captured but also help to avoid channeling of resources and time to fruitless breeding activities. Thus, this study was carried out to determine farmer's awareness and perceptions to changing rainfall patterns across two rice growing states in south western Nigeria. We also assessed their preferred traits in new upland rice varieties.

\section{Materials and Methods}

\subsection{Description of Study Area}

The study was carried out in Ekiti and Ogun States, located in southwestern Nigeria. Southwestern Nigeria is home to Yoruba speaking tribes. Ekiti and Ogun States (Fig. 1) are agrarian states dominated by rainfed upland rice ecosystem and it contributes about $16 \%$ of total rice output in Nigeria. Ofada rice cultivars characterized by short grain and sweet aroma are the predominant upland rice materials across the two states. It is cultivated across southwestern Nigeria and is known to attract high premium for rice farmers and traders across the region and surrounding states (PrOpCom, 2007).

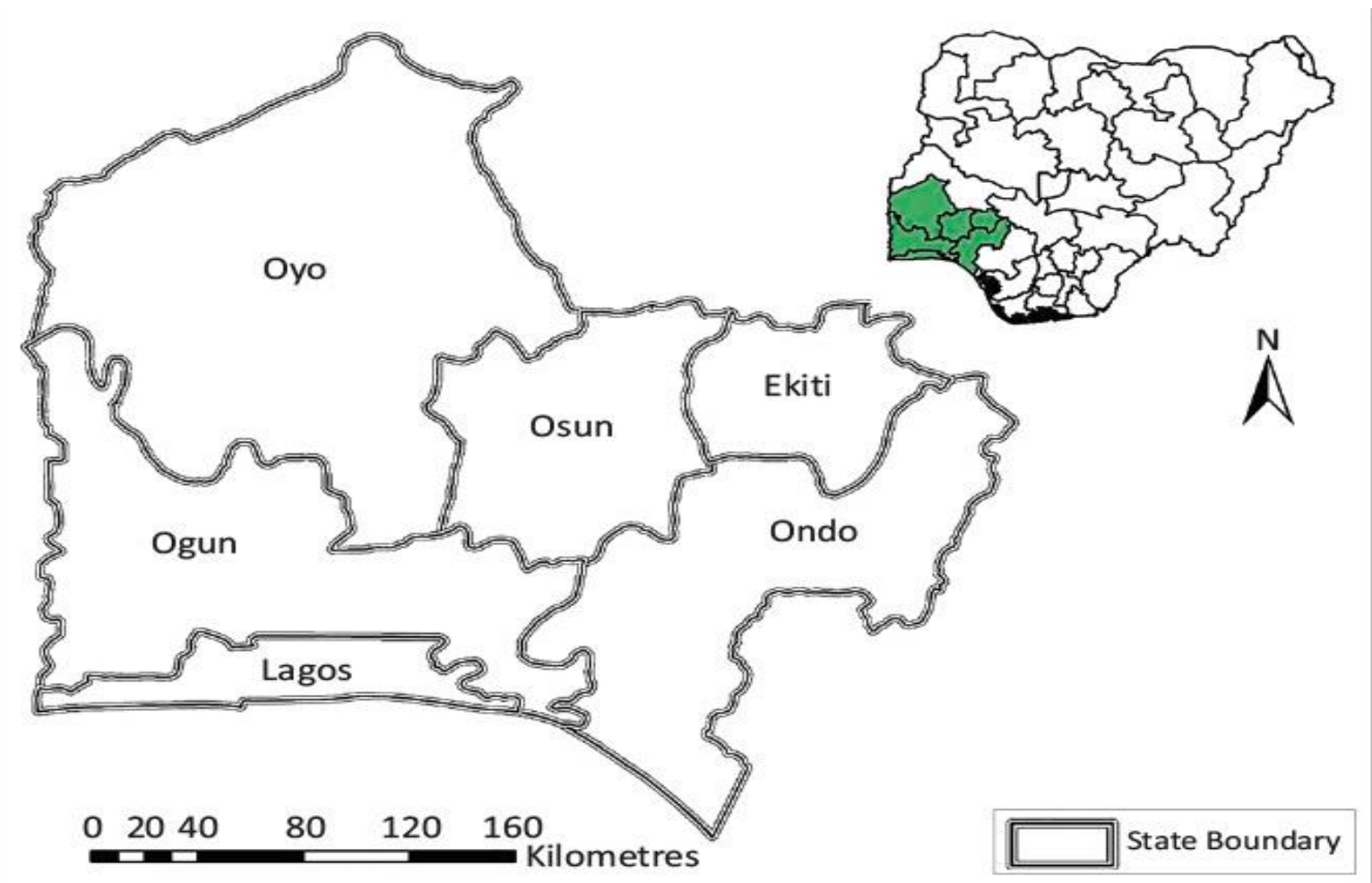

Figure 1. Map of the study area 
Southwestern Nigeria has tropical climate with two distinct seasons: rainy season (April-October) and dry season (November-March). The peak rainy season is usually around June accompanied by two to three weeks break in August. A short period of rainy season comes up from September until the commencement of dry season popularly referred as Hamattan in November. The region is also characterized by bimodal rainfall with mean annual rainfall of the two states ranging between $1200-1400 \mathrm{~mm}$ and a mean annual temperature of about $27^{\circ} \mathrm{C}$. The vegetation spans from rain forest in the south to Guinea savanna in the north with the soil largely rich in organic minerals. Ogun state also has an extensive industrial encroachment leading to high population density due to its proximity to Lagos state, the business hub of the country.

\subsection{Sampling Procedures}

The study was carried out from 2015 through 2016. Three upland rice growing communities from three local government areas were selected from Ekiti while two local government areas comprising of four communities were selected in Ogun state. The communities chosen for survey in each state were identified and selected based on background information provided by extension agents and President of Rice Farmers Associations (RFA) in charge of the communities. The head of programme for Agricultural Development Programme (ADP) Ado Ekiti (capital of Ekiti state) scheduled meetings with upland rice farmers through the assistance of extension agents overseeing each of the chosen communities while in Ogun state, the President of RFA facilitated the meetings through his members in neighboring communities. No restriction was placed on the number of rice farmers interviewed in a village since the study focused strictly on upland rice farmers. In all, 119 farmers comprising of 82 upland rice farmers from Ekiti State and 37 farmers from Ogun State participated in the study.

It is vital to note that two states out of the six states that make up southwest Nigeria may not fully capture the interest and views of all upland rice farmers across the region on the focus of this study. However, we believe that the information derived from this study based on the two states is important on account that this will help rice breeders to focus their breeding efforts towards incorporating the preferred traits identified in this study to create new adoptable upland rice varieties that are most adaptable to south western regions of Nigeria. Furthermore, this can serve as a useful base for further studies on the effects of changing rainfall pattern on rice production in the region.

\subsection{Data Collection and Analysis}

To understand farmers awareness on changing rainfall pattern in their environment and preferred choices in a new rice variety, Participatory Rural Appraisal (PRA) techniques involving focused group discussions (with semi-structured questions), iteration, probing, preference ranking and pair wise ranking were employed according to Efisue et al. (2008). Data was generated through a questionnaire administered to farmers by facilitators. Information was gathered on number and types of rice varieties, seed sources, important variety characteristics, major constraints to upland rice production, farmers' knowledge of changing rainfall pattern with crop growth stages most affected by drought stress in the field. 


\section{Macrothink

Focused group discussions and structured questionnaires were deployed in such a way that enabled the farmers express themselves without bias from friends or other members of the community. The farmers listed varieties they cultivate, ranked them, and identified traits they preferred in new rice varieties. Furthermore, the facilitators also used pictures and cards that had drawings representing various traits to assist the farmers during discussions. For pair-wise ranking, traits of interest were compared pair by pair; groups were asked which of the two they preferred, and why.

Statistical analyses were performed in SPSS (Release 15.0) computer package, and R statistical package 2017. Relationships were estimated through frequencies, descriptive statistics. Chi-square analysis was used to test for significant relationship between data from the two states. Data were transformed where necessary before subjecting to analysis.

Lower number (37 upland rice farmers) of respondents were interviewed in Ogun state compared to Ekiti state, because most of the farmers live in small farm settlements with difficult terrain far away from their villages.

\section{Results}

\subsection{Socio Economic Characteristics}

The age of respondents varied from 21 to 71 years across the two states with $76.8 \%$ and $80 \%$ of respondents being male in Ekiti and Ogun states, respectively (Table 1). All respondents in Ogun State were married while $92.6 \%$ of respondents in Ekiti were married. Mean household size was about 6 persons per household with an average farm size of 4.4 hectares (Table 1). About 58\% and $63 \%$ of those interviewed at Ekiti and Ogun States respectively had vocational training while all the famers interviewed in Ogun State and $87.7 \%$ of those in Ekiti State had regular contact with extension officers. However, personal observation revealed that some of the Ofada rice farmers in Ogun State lived in farm settlements far away and isolated from the villages with poor telecommunication and road networks systems thereby creating a huge challenge for most extension agents to access them easily. It was also observed from the survey that most of the upland rice farmers in communities having regular contact with extension officers from the state Agricultural Development Agency (ADP) are more updated on the current trends in rice production compared to those having less contact with extension officers. 


\section{Macrothink}

Journal of Agricultural Studies

ISSN 2166-0379

2019, Vol. 7, No. 3

Table 1. Distribution of respondents by socio-demographic Characteristics

\begin{tabular}{lcccc}
\hline $\mathrm{N}=119$ & \multicolumn{2}{c}{ Ekitti State } & \multicolumn{2}{c}{ Ogun State } \\
\hline & No. & $\%$ & No. & $\%$ \\
\hline Gender & & & & \\
Male & 63 & 76.8 & 27 & 80.0 \\
Female & 19 & 23.2 & 7 & 20.0 \\
Marital Status & & & & \\
Married & 75 & 92.6 & 34 & 100.0 \\
Single & 6 & 7.4 & 0 & \\
Vocational training & 49 & 57.6 & 17 & 62.5 \\
Contact with extension officers & 71 & 87.7 & 34 & 100.0 \\
Belong to cooperative group & 55 & 69.6 & 34 & 100.0 \\
Practice upland rice system & 77 & 90.6 & 32 & 86.4 \\
\hline
\end{tabular}

Absentia=one

\subsection{Constraints to Upland Rice Production}

Many constraints to rice production were listed by the farmers during the focus group interactions (Table 2). Pests (91.6\%), and weed infestations (86\%) were the most important biotic stresses limiting upland rice production in the two states followed by drought stress (76.6\%). Flooding (29\%) was the least important constraint identified (Table 2). Farmers in areas frequently visited by extension officers had better understanding of how to manage most of the constraints highlighted in this study through application of basic agronomic practices such as delayed planting until when the rains are stable and the use of improved rice varieties.

Table 2. Constraints to upland rice production across the two states

\begin{tabular}{lll}
\hline Constraints & No. & $\%$ \\
\hline Pest & 98 & 91.6 \\
Weed & 92 & 86.0 \\
Drought & 82 & 76.6 \\
Lack of farm machineries & 68 & 63.6 \\
High cost of input & 65 & 60.7 \\
Poor soil fertility & 63 & 58.9 \\
Diseases & 55 & 51.4 \\
Lack of access to improved seed & 51 & 47.7 \\
High cost of improved seed & 50 & 46.7 \\
land shortage & 49 & 45.8 \\
Erosion & 40 & 37.4 \\
Flooding & 31 & 29.0 \\
\hline
\end{tabular}

$N=19$

\subsection{Respondents' Knowledge of Changes in Rainfall Pattern}

The frequency of rainfall in Ogun State was observed to be higher than in Ekiti (Table 3). Most respondents agreed that the rainfall patterns have changed over the past 10 years with a decrease in amount of rainfall during crop growing periods in the field. 


\section{Ml Macrothink}

Journal of Agricultural Studies

ISSN 2166-0379

2019, Vol. 7, No. 3

Table 3. Distribution of respondents based on their knowledge of changes in rainfall pattern in the two states

\begin{tabular}{|c|c|c|c|c|c|}
\hline \multirow[t]{2}{*}{$\mathrm{N}=119$} & \multicolumn{2}{|c|}{ Ekiti } & \multicolumn{2}{|c|}{ Ogun } & \multirow[b]{2}{*}{ Chi square } \\
\hline & No & $\%$ & No & $\%$ & \\
\hline \multicolumn{6}{|l|}{ Frequency of rainfall on weekly basis } \\
\hline Once & 20 & 31.7 & 5 & 15.8 & \multirow{3}{*}{0.0001242} \\
\hline Twice & 22 & 34.9 & 7 & 21.1 & \\
\hline Thrice & 21 & 33.3 & 20 & 63.2 & \\
\hline In agreement to incidence of drought within crop growing period & 63 & 90 & 19 & 68.8 & \\
\hline In agreement to observable changes in rainfall pattern & 50 & 90.9 & 28 & 100 & \\
\hline \multicolumn{6}{|l|}{ Changes in rainfall pattern between year 2000- 2014} \\
\hline The same & 10 & 13.3 & 0 & & \multirow[t]{3}{*}{0.0007505} \\
\hline Increased & 29 & 38.7 & 16 & 47.4 & \\
\hline Decreased & 36 & 48 & 17 & 52.6 & \\
\hline \multicolumn{6}{|l|}{ Negative impacts of drought stress in recent years } \\
\hline Low & 28 & 37.3 & 2 & 5.6 & \multirow[t]{3}{*}{ 7.21E-04 } \\
\hline High & 33 & 44 & 26 & 83.3 & \\
\hline Severe & 14 & 18.7 & 3 & 11.1 & \\
\hline \multicolumn{6}{|l|}{$\begin{array}{l}\text { Accurate prediction of the likelihood that it will rain within a } \\
\text { specific time of the day compared to } 10 \text { years ago }\end{array}$} \\
\hline No & 64 & 95.5 & 37 & 100 & \multirow[t]{2}{*}{0.09516} \\
\hline Yes & 3 & 4.5 & 0 & 0 & \\
\hline
\end{tabular}

$P=0.5$

3.4 Crop Development Stages Most Affected by Drought Stress in Farmers' Fields and Deployed Techniques to Mitigate the Effects

Multi response analysis was carried out to determine crop growth stages (from seedling to grain filling) most affected by drought stress under farmers' field (Table 4). In Ekiti State, the growth stages most affected by drought stress were seedling (47.5\%), flowering (43.9\%), and grain filling stages $(40.4 \%)$. However, most respondents from Ogun State agreed that reproductive stage drought stress had the most devastating effect on rice yields within their communities. Less than $10 \%$ of the farmers use improved rice varieties and also study the weather to ensure stability of rainfall before planting. However, majority of the farmers believed in consulting God the creator for rain or making sacrifices to appease the gods in times of drought stress. None of the interviewed farmers had access to irrigation facilities and so they depend strictly on rainfed as source of water in their rice fields. 
Table 4. Crop developmental stages most affected by drought stress in farmers' field

\begin{tabular}{|c|c|c|c|c|}
\hline & & & Res & nses \\
\hline STATE & Villages & Crop growth stage & No. & $\%$ \\
\hline \multirow{10}{*}{ EKITI } & \multirow{3}{*}{ EGBEMO } & Seedling & 29 & 47.5 \\
\hline & & Tillering & 5 & 8.2 \\
\hline & & Flowering & 27 & 44.3 \\
\hline & & & & \\
\hline & \multirow{3}{*}{ IROKO EKITI } & Seedling & 17 & 41.5 \\
\hline & & Tillering & 6 & 14.6 \\
\hline & & Flowering & 19 & 43.9 \\
\hline & \multirow{3}{*}{ IWAJI EFON } & Seedling & 18 & 38.3 \\
\hline & & Tillering & 10 & 21.3 \\
\hline & & Flowering & 19 & 40.4 \\
\hline \multirow{6}{*}{ OGUN } & AJANA ODO & Flowering & 10 & 100 \\
\hline & JOGA ORILE & Flowering & 7 & 100 \\
\hline & \multirow[b]{2}{*}{ MOLOKO ASIPA } & & & \\
\hline & & $\begin{array}{l}\text { Flowering } \\
\text { Grain filling }\end{array}$ & $\begin{array}{l}7 \\
10\end{array}$ & $\begin{array}{l}100 \\
60\end{array}$ \\
\hline & \multirow{2}{*}{ OGBE ERUKU } & Flowering & 4 & 50 \\
\hline & & Grain filling & 3 & 50 \\
\hline
\end{tabular}

\subsection{Preferred Grain Size, Shape, Grain Color and Plant Height across the Two States}

Most upland rice farmers in Ekiti state preferred medium plant heights with white long and bold grains (Table 5). In Ogun state, 50\% of the respondents preferred upland rice varieties with white, long and large grains while $45 \%$ of the respondents preferred white, short-round grain. Most of the farmers in the two states preferred medium plant height and showed less preference for semi-dwarf or tall varieties.

Table 5. Distribution of respondents for their preferred plant height and rice grain shape

\begin{tabular}{|c|c|c|c|c|c|}
\hline \multirow[t]{2}{*}{$\mathrm{N}=119$} & \multicolumn{2}{|c|}{ EKITI } & \multicolumn{2}{|c|}{ OGUN } & \multirow[b]{2}{*}{ Chi square } \\
\hline & No. & $\%$ & No. & $\%$ & \\
\hline \multicolumn{6}{|c|}{ Grain size and shape } \\
\hline Long and slender & 4 & 5 & 0 & 0 & \\
\hline Long and bold & 52 & 69 & 17 & 50 & $1.00 \mathrm{E}-04$ \\
\hline Medium & 19 & 25 & 2 & 5 & \\
\hline Short and round & 0 & 0 & 15 & 45 & \\
\hline \multicolumn{6}{|l|}{ Grain colors } \\
\hline Red & 7 & 9.2 & 5 & 15 & 0.004501 \\
\hline White & 55 & 72 & 17 & 50 & \\
\hline Gold & 14 & 18 & 12 & 35 & \\
\hline \multicolumn{6}{|l|}{ Plant height } \\
\hline Dwarf & 0 & 0 & 9 & 25 & $1.00 \mathrm{E}-04$ \\
\hline Medium & 70 & 92 & 26 & 75 & \\
\hline Tall & 6 & 7.9 & 0 & 0 & \\
\hline
\end{tabular}

$$
P=0.5
$$

Table 6 shows the various attributes associated with each of the listed upland rice varieties cultivated across the different communities. Significant level of difference was recorded for choice of plant height and grain related traits among the upland rice farmers from the two states used in this study. The desired traits that determine the acceptability of most popular 
upland rice varieties cultivated and identified in this study were good tastes, seed shape, earliness, tolerance to diseases and pest, high yielding and resistance to lodging (Table 6).

Table 6. Preferred traits of some popular upland rice varieties cultivated across the two states of study

\begin{tabular}{ll}
\hline OFADA RICE & \\
\hline Likes & Dislikes \\
\hline $\begin{array}{l}\text { Good taste and high sales } \\
\text { Good taste }\end{array}$ & $\begin{array}{l}\text { Late maturing } \\
\text { Tall and prone to lodging } \\
\text { Good grain appearance after milling } \\
\text { Short and round seed highly preferred by consumers }\end{array}$ \\
\hline ITA 150 & Susceptible to drought stress, diseases and pest \\
\hline Likes & Dislikes \\
\hline $\begin{array}{l}\text { High yielding } \\
\text { Early }\end{array}$ & None \\
$\begin{array}{l}\text { Good market returns } \\
\text { Highly adaptable }\end{array}$ & Light brown colour of milled grains \\
Tolerant to drought & \\
Good grain appearance after milling & \\
\hline IGBEMO RICE & \\
\hline Likes & \\
\hline Long grain and high yield & Dislikes \\
medium height & Moderately susceptible to diseases and pest \\
High sales & \\
Good grain appearance after milling & \\
\hline NERICA 8 & \\
\hline Likes & Dislikes \\
\hline High yielding & Poor grain appearance after milling \\
Medium height & Low market demand \\
Resistance to major abiotic and biotic stresses & \\
\hline
\end{tabular}

\section{Discussion}

The socio-economic characteristics of respondents indicated that majority of rice farmers in the two states were male thereby confirming dominance of male farmers in upland rice cultivation over women in the study areas. The gender ratio in favor of men might be attributed to the hard labor involved in activities of upland rice production in the region due to use of crude technologies. Similar findings have been reported in other studies on the role of gender in rice production. This agrees with the findings of Saka and Lawal (2009); and Owolabi et al. (2015) but disagrees with the findings of Afolabi (2008) who reported gradual dominance of women over arable crop cultivation in Nigeria. However, from their survey in the Sikasso region of Mali, Efisue et al. (2008) reported the dominance of men in upland rice production while the women dominated lowland and irrigated rice production systems.

The farmers' family sizes also gave an indication of the amount of labour force that could be available for agricultural activities. Average family size reported in this study is in line with Owolabi et al. (2015) who reported 4-6 persons in a household from a study conducted with rice farmers in Ekiti State, Nigeria. Ogun State had more educated farmers compared to Ekiti State. Higher number of educated farmers in Ogun State with a well-organized farmers' association might have contributed to the willingness indicated by majority of the farmers to 
interact with extension officers. Muneer (2008) reported that educated farmers were more innovative and open to new technologies than non-educated ones. The findings of this study with reference to Ekiti state contradict those of Arimi (2014) who reported that a small number of farmers in southwest Nigeria $(29.8 \%)$ had contacts with extension agents.

Constraints such as weeds, drought, pest and diseases affecting upland rice production as observed in this study have been reported earlier by different authors. Singh et al. (1997); Longtau, (2003) and Adebayo et al. (2012) reported pests, weeds and drought stress as the major agronomic constraints to rice production in Nigeria. In a different study, Edeh et al. (2011) observed variability in rainfall pattern as a significant environmental risk factor affecting rice production in Ebonyi State of Nigeria. This implies that these constraints if not properly managed, might lead to poor yield resulting in loss of income and reduced standards of living for the entire farmer's household.

Higher frequency of rainfall experienced in Ogun State compared to Ekiti State might be attributed to the fact that Ekiti is closer to the savanna belt than Ogun State that is located in the rain forest belt of western Nigeria. General decline in annual rainfall across many parts of Nigeria has been reported in previous research findings (Odjugo, 2009; Umar, 2011). The findings of Adebayo et al. (2012) showed that some negative effects of varying rainfall pattern include reduced crop yield and frequent dry spells during crop growing seasons in the field. This also corroborates the results of Kimani et al. (2011) that drought stress resulting from forest cover depletion caused reduced rainfall during the rice growing seasons in Kenya. Boyan et al. (2008) summarized that changes in rainfall pattern were already felt in our environments in many ways and in different dimensions further confirming the results of this study.

Most farmers from the two states reported that highest yield loss is usually recorded with the occurrence of drought stress at reproductive stage of their crop in the field. This confirms the reports of O'Toole (1982) and Boonjung (1993) that the rice plant is most affected by drought stress between the stages of flowering and grain filling. However, most rice farmers across the two states, despite being aware of the devastating effects of drought stress at different developmental stages of their rice crop, were less equipped with the right facilities and technical know-how needed to check the negative effects of drought stress in their fields. Most of the farmers relied on prayer and sacrifices offered to the gods to intervene and mitigate the adverse effects of drought stress in their rice field rather than the use of improved high yielding, early maturing, drought tolerant varieties that are feasible and sustainable in the long run. The results of this finding contradict the reports of Adebayo et al. (2012) that majority of farmers in Adamawa State of Nigeria employed different agronomic practices to alleviate the negative impacts of drought stress in the region compared to prayers as observed in this study. This might be attributed to the fact that Adamawa State is located in the Sudan savannah agro-ecology of Nigeria characterized by minimal rainfall distribution all year round thus compelling farmers to develop and adopt improved farming techniques that enables them to adapt to their drought prone environments.

Dalton (2004) reported that yield is not the only determinant factor controlling the level of 
adoption of a new rice variety by farmers across sub-Sahara Africa. Most farmers in this survey preferred medium plant height to semi dwarf and tall varieties due to backache usually induced by stress associated with bending down to harvest semi dwarf varieties while tall ones are highly susceptible to lodging. These findings agree with Efisue et al. (2008); and Oko et al. (2012) but deviate from the popular opinion that preferred traits for upland rice varieties are plants with semi dwarf architecture producing long and slender grains as promoted by most researchers and authors.

Most farmers still maintain and cultivate their landraces across the communities visited despite the low yield recorded per hectare. The NERICAs and ITA 150 were developed and released to African rice farmers by AfricaRice and IITA respectively while the Ofada and Igbemo rice are adapted local upland rice cultivars named after the two rice growing communities "OFADA and IGBEMO towns" where they are largely cultivated in south western Nigeria (PrOpCom, 2007). The "FUNAABORs 1 and 2" are released upland rice varieties in Nigeria developed by Federal University of Agriculture, Abeokuta, Ogun State Nigeria through mass selection and purification of existing local Ofada rice collections from farmers field in south western Nigeria (Showemimo et al., 2011). However, the most popular and cultivated varieties in the two states covered were the low yielding unimproved upland rice landraces rather than the improved high yielding genotypes. This agrees with Dalton (2004) that yield is not the only determinant of farmers' willingness to adopt and cultivate a new variety but should be complemented by other agronomic traits of interest such as aroma, good plant architecture (resistance to lodging), grain shape and quality as preferred by the farmers and end-users.

The differences in choices between the two states in terms of grain characteristics might be due to the types of upland rice varieties that are already established in each of the localities over time. The two upland rice cultivars Igbemo White and Igbemo Red prevalent in Ekiti State are of long and bold sized grain while Ofada rice cultivar that is widely cultivated across Ogun State is characterized by short and round grains. This emphasizes the need for rice breeders in the region to employ breeding strategies directed towards breeding for improved grain quality in addition to high yield potential. No strong reasons were reported by the farmers for the preferred grain shapes and sizes across the visited communities. Although most of the improved rice varieties had yield advantage over the landraces and were also more tolerant to most agronomic constraints prevalent in the study areas, unimproved low yielding landraces were still popular among farmers. This might be attributed to the fact that most of these new improved varieties were not bred considering the needs of the end users such as grain shape, grain quality and plant architecture that may vary across regions and localities. For instance, most upland rice farmers in the study areas reported that even though the improved varieties are high yielding and tolerant to major diseases and pests in the region, they had poor taste and appearance after cooking.

\subsection{Importance of Findings to Upland Rice Genetic Improvement in Nigeria}

The impact of changing unpredictable rainfall pattern such as drought stress and its devastating effects on the environment and agricultural output has been reported in recent 
years (Adejuwon, 2004: Owolabi et al., 2015). Rice production in Nigeria is not exempted from impacts of the complex dynamics associated with changing rainfall pattern (Ajetomobi et al., 2011). From the results of this study, it can be deduced that indigenous upland rice farmers in south western Nigeria were aware of the changes in rainfall pattern within their environments but are handicapped on how best to adapt to these changes. This underscores the need to develop new resilient upland rice varieties adaptable to the changing environments with full participation of the farmers in the developmental process. Such approach will ensure that research efforts and resources are directed to create improved varieties that will address farmers' needs (Morris and Bellon, 2004).

Prior knowledge of farmers preferred traits in upland rice varieties as identified in this study and successful incorporation of these traits into farmers' adapted varieties will facilitate adoption of new improved varieties by farmers. The low adoption rate recorded for most released improved upland rice varieties in Nigeria, despite giving higher yields compared to the local cultivars might be attributed to the absence of desired traits such as good plant architecture and grain quality preferred by farmers and consumers in these regions. Increase in rice production output will still remain a big challenge unless rice breeders in the region develop and distribute improved varieties with desired attributes preferred by the local rice farmers and end users.

\section{Conclusions and Recommendations}

Farmer's awareness to changes in rainfall pattern and their preferred agronomic traits in a new upland rice variety were determined across the rice growing communities covered in this study. Most of the upland rice farmers were aware of changes in rainfall pattern resulting to decreased amount of rainfall during the crop growing seasons. However, majority of the farmers are poorly equipped to mitigate the devastating impacts of drought stress in their upland rice fields. Farmers across the two states preferred medium plant height with Ogun State farmers exhibiting higher preference for round and medium grain shape whereas long and large grain size was preferred by farmers in Ekiti State. It is vital to encourage creation of new varieties with farmers' preferred traits that are also adaptable to specific rice growing region using participatory plant breeding approaches that allow farmers to contribute their own quota from the early developmental stages of the breeding programme. Incorporation of farmers preferred traits such as plant architecture and grain qualities complemented by high grain yield under drought stress and non-stress environments in upland rice breeding programs as highlighted in this study might enhance ease of adoption.

\section{Acknowledgements}

We are grateful to the Alliance for a Green Revolution in Africa (AGRA) for providing funds for this study through the West African Centre for Crop Improvement (WACCI), University of Ghana Ph.D fellowship; The authors also appreciate Mr Omole and Mr Oni (Extension officers with Ekiti state Agricultural Development Programme; and Pa Adenekan (president of farmers rice Association, Ogun state chapter) for organizing the rice farmers that participated in this study. Special thanks to Dr. (Mrs) .B.A. Awotide of IITA, for her wonderful inputs in structuring the questionnaire. 


\section{References}

Adebayo, A. A., Onu, J. I., Adebayo, E. F., \& Anyanwu, S. O. (2012). Farmers Awareness, Vulnerability and Adaptation to Climate Change in Adamawa State Nigeria. British journal of arts and social sciences, 9(2), 104-115.

Adejuwon, S.A. (2004). Impact of climate variability and climate change on crop yield in Nigeria. Contributed paper to Stakeholders workshop on Assessment of Impact and Adaptation to Climate Change (AIACC), 2-8.

Afolabi, M. M. (2008, June). Women as pillars of national economy in Nigeria: A study of economic activities of rural women in six local government areas of Ondo State. In IAFFE Summer Conference, International Association for Feminist Economics, Torino, Italy (Vol. 19).

Ajah, J., \& Ajah, F. C. (2014). Socio-economic Determinants of Small-scale Rice Farmers' Output in Abuja, Nigeria. Asian Journal of Rural Development,4(1), 16-24. https://doi.org/10.3923/ajrd.2014.16.24

Ajala, A. S., \& Gana, A. (2015). Analysis of challenges facing rice processing in Nigeria. Journal of Food Processing, 16(3), 285- 296. https://doi.org/10.1155/2015/893673

Ajetomobi, J. O., Abiodun, A., \& Hassan, R. (2011). Impacts of climate change on rice agriculture in Nigeria. Tropical and Subtropical Agroecosystems, 14(2), 613-622.

Akinbile, C. O. (2010). Behavioural pattern of upland rice agronomic parameters to variable water supply in Nigeria. Journal of Plant Breeding and Crop Science, 2(4), 073-080.

Ali, S., Liu, Y., Ishaq, M., Shah, T., Ilyas, A., \& Din, I. (2017). Climate change and its impact on the yield of major food crops: Evidence from Pakistan. Foods, 6(6), 39. https://doi.org/10.3390/foods6060039

Aondoakaa, M. K. (2013). Prospects and Challenges of Indigenous Investors in the Actualization of Rice Revolution Plan. A Paper Presented at the 2013 International Engineering Conference and Exhibition Tagged "Abuja 2013" of the Nigerian Society of Engineers holding between 9th - 13th December 2013 at the International Conference Centre, Abuja, Nigeria.

Apata, T. G., Ariyomo, T., \& Adebisi, B. R. (2018). The economic analysis of rice and cassava stable food-crops processing in Ekiti State, Nigeria. Bulgarian Journal of Agricultural Science, 24(5), 768-776.

Arimi, K. (2014). Determinants of climate change adaptation strategies used by rice farmers in Southwestern, Nigeria. Journal of Agriculture and Rural Development in the Tropics and Subtropics (JARTS), 115(2), 91-99.

Atlin, G. N., Cooper, M., \& Bjørnstad, A. (2006). A comparison of formal and participatory breeding approaches using selection theory. Euphytica, 122(3), 463-475.

Atlin, G. N., Lafitte, R., Venuprasad, R., Kumar, A., \& Jongdee, B. (2004). Heritability of rice 
yield under stress, correlations across stress levels, and effects of selection: implications for drought tolerance breeding. In: Poland D, Sawkins M, Ribaut JM, Hoisington D, eds. Resilient crops for water-limited environments. Proceedings of a Workshop at Cuernavaca, Mexico May 24-28, 2004. Mexico: CIMMYT, 85-87.

https://doi.org/10.1023/A:1017557307800

Bernier, J., Atlin, G. N., Serraj, R., Kumar, A., \& Spaner, D. (2008). Breeding upland rice for drought resistance. Journal of the Science of Food and Agriculture, 88(6), 927-939. https://doi.org/10.1002/jsfa.3153

Boonjung, H. (1993). Modelling growth and yield of upland rice under water limiting conditions. PhD thesis, The University of Queensland.

Boyan, E., Deressa, T., Gbetibovo, G., \& Ringler, C. (2008). Determinants of climate change in Ethiopia and South Africa. South Africa: International Food Policy Research Institute (IFPRI) and CGIAR Challenge Programme on Water and Food.

Cobb, J. N., Juma, R. U., Biswas, P. S., Arbelaez, J. D., Rutkoski, J, Atlin, G., .. \& Ng, E. H. (2019). Enhancing the rate of genetic gain in public-sector plant breeding programs: lessons from the breeder's equation. Theoretical and applied genetics, 132(3), 627-645. https://doi.org/10.1007/s00122-019-03317-0

Dalton, T. J. (2004). A household hedonic model of rice traits: economic values from farmers in West Africa. Agricultural Economics, 31(2-3), 149-159.

https://doi.org/10.1111/j.1574-0862.2004.tb00253.x

Dauda, S. M., \& Dzivama, A. U. (2004). Comparative performance of a locally developed rice thresher with an imported Votex Rice Fan. In Proceedings of the 5th International Conference of the Nigerian Institution of Agricultural Engineers, Ilorin (Vol. 26, pp. 29-32).

Efisue, A., P. Tongoona, J., Derera, A. Langyintuo, Laing M., \& Ubi, B. (2008). Farmers'perceptions on rice varieties in Sikasso region of Mali and their implications for rice breeding. Journal of Agronomy and Crop Science, 194, 393-400.

https://doi.org/10.1111/j.1439-037X.2008.00324.X

Fashola, O. O., Oladele, O. I., Aliyu, J., \& Wakatsuki, T. (2006). Dissemination of sawah rice technology to farmers cultivating inland valleys in Nigeria. Proceedings of the Asian Pacific Extension Network, 6-8.

Federal Ministry of agriculture and Rural Development, (2012). Agricultural Transformation Agenda: Repositioning Agriculture to drive Nigeria's Economy.

Gumm, D. (2010). Nigeria: Climate change to affect rice yields. Vanguard, August 19. Retrieved on September 20th, 2011 from http://allafrica.com/nigeria/climate.

Hoffmann, U. (2013). Section, B. Agriculture - a Key Driver and a Major Victim of Global Warming, in: Lead Article, in: Chapter 1, in Hoffmann. 2013; 3, 5.

Imolehin, E. D. (1991). Rice improvement and production in Nigeria. Paper presented at WARDA upland breeding task force workshop, Bouake, code. 
Kimani, J. M., Tongoona, P., Derera, J., \& Nyende, A. B. (2011). Upland rice varieties development through participatory plant breeding. Journal of Agricultural and Biological Science, 6(9), 39-49.

Kumar, A., Dixit, S., Ram, T., Yadaw, R. B., Mishra, K. K., \& Mandal, N. P. (2014). Breeding high-yielding drought-tolerant rice: genetic variations and conventional and molecular approaches. Journal of Experimental Botany, eru363. https://doi.org/10.1093/jxb/eru363

Longtau, S. R. (2003). Multi-agency partnerships in West African Agriculture. A review and description of rice production systems in Nigeria. Jos, Nigeria: Eco-systems Development Organization (EDO-DFID) report, 50.

Morris, M. L., \& Bellon, M. R. (2004). Participatory plant breeding research: opportunities and challenges for the international crop improvement system. Euphytica, 136(1), 21-35. https://doi.org/10.1023/B:EUPH.0000019509.37769.b1

Muneer, S. E. T. (2008). Factors affecting adoption of agroforestry farming system as a mean for sustainable agricultural development and environment conservation in arid areas of Northern Kordofan state, Sudan. Saudi Journal of Biological Sciences, 15(1), 137-145.

O'Toole, J. C. (1982). Adaptation of rice environments. Drought resistance in crops with emphasis on rice, 195.

Odjugo, P. A. O. (2009). The impact of climate change on water resources: Global and Nigerian analysis. FUTY Journal of the Environment, 4(1), 59-77.

https://doi.org/10.4314/fje.v4i1.48005

Ogundele, O. O., \& Okoruwa, V. O. (2006). Technical efficiency differentials in rice production technologies in Nigeria (No. RP_154). African Economic Research Consortium.

Oko, A. O., Ubi, B. E., \& Efisue, A. A. (2012). A Comparative Study on Local and Newly Introduced Rice Varieties in Ebonyi State of Nigeria based on Selected Agronomic Characteristics. International Journal of Agriculture and Forestry,2(1), 11-17. https://doi.org/10.5923/j.ijaf.20120201.03

Oladimeji, Y. U., \& Abdulsalam, Z. (2013). Analysis of technical efficiency and its determinants among small scale rice farmers in patigi local Government area of kwara state, Nigeria. IOSR. Journal of Agricultural and Veterinary Science (IOSR-JAVS), 3(3), 34-39. https://doi.org/10.9790/2380-0333439

Olanrewaju, R. M., Tilakasiri, S. L., \& Oso, C. (2017). Climate Change and Rice Production: A Case Study in Ekiti State, Niger. Journal of Agricultural Sciences-Sri Lanka, 12(2). https://doi.org/10.4038/jas.v12i2.8228

Ologbon, O. A. C., Ikheloa, E. E., \& Akerele, E. O. (2012). Adoption of 'Ofada'rice variety and technical efficiency of rice-based production systems in Ogun state, Nigeria. World Journal of Agricultural Sciences, 8(6), 624-631.

O'Toole, J. C. (1989). Breeding for drought resistance in cereals: emerging new technologies. Baker, FWG (eds.). Drought resistance in cereals. Proceedings of a symposium held in Cairo, 


\section{Ml Macrothink}

Egypt, 28-30 November 1988. Wallingford (United Kingdom). CAB International. 1989. p. 81-94. In ^ TBaker, FWG (eds.). Drought resistance in cereals. Proceedings of a symposium held in Cairo, Egypt, 28-30 November 1988. Wallingford (United Kingdom). CAB International. 1989. p. 81-94^ C1989 (No. 92-002367. CIMMYT.).

Owolabi, K. E., Jonathan, K. U., Ayodele, O. V., \& Wole-Alo, F. I. (2015). The Perception and Adaptation Strategies to Climate Change by Rice Farmers in Ekiti State, Nigeria. https://doi.org/10.9734/BJAST/2015/16707

PrOpCom, New Nigeria Foundation. "Ofada Baseline Survey." Submitted to PrOpCom. Nigeria: PrOpCom, 2007.

Sahebi, M., Hanafi, M. M., Rafii, M. Y., Mahmud, T. M., Azizi, P., Osman, M., .. \& \& Miah, G. (2018). Improvement of drought tolerance in rice (Oryza sativa L.): Genetics, genomic tools, and the WRKY gene family. BioMed research international.

https://doi.org/10.1155/2018/3158474

Saka, J. O., \& Lawal, B. O. (2009). Determinants of adoption and productivity of improved rice varieties in southwestern Nigeria. African Journal of Biotechnology, 8(19).

Showemimo, F. A., Gregorio, G., Olowe, V. I. O., Ukwungwu, M. N., Maji, A., Adigbo, S. O., ... \& Awe, C. A. (2011). Varietal release: Release of two dual purpose ofada rice varieties (Funaabor-1 and Funaabor-2) by federal university of agriculture, abeokuta (Funaab). J Agric Sci Environ, 11(2), 122-123.

Singh, B. N., Fagade, S., Ukwungwu, M. N., Williarn, C., Jagtap, S. S., Oladimeji, O., ... \& Okhidievbie, O. (1997). Rice growing environments and biophysical constraints in different agroecological zones of Nigeria. Meterological Journal, 2(1), 35-44.

Umar, A. T. (2011). Climate change in Nigeria: Evidence from meteorological parameters. In Association of Nigeria Geographers conference at Usman Danfodio University, Sokoto.

Van Oort, P. A., \& Zwart, S. J. (2018). Impacts of climate change on rice production in Africa and causes of simulated yield changes. Global Change Biology, 24(3), 1029-1045. https://doi.org/10.1111/gcb.13967

Witcombe, J. R., Joshi, A., \& Goyal, S. N. (2003). Participatory plant breeding in maize: A case study from Gujarat, India. Euphytica, 130(3), 413-422. https://doi.org/10.1023/A:1023036730919

World Bank Group. 2007. Participatory Rural Appraisal.

\section{Copyright Disclaimer}

Copyright for this article is retained by the author(s), with first publication rights granted to the journal.

This is an open-access article distributed under the terms and conditions of the Creative Commons Attribution license (http://creativecommons.org/licenses/by/4.0/). 